\title{
Regulation of PTEN expression by noncoding RNAs
}

\author{
Wang Li, Ting Zhang, Lianying Guo and Lin Huang ${ }^{*}$
}

\begin{abstract}
Phosphatase and tensin homologue (PTEN) triggers a battery of intracellular signaling pathways, especially PI3K/Akt, playing important roles in the pathogenesis of multiple diseases, such as cancer, neurodevelopmental disorders, cardiovascular dysfunction and so on. Therefore PTEN might be a biomarker for various diseases, and targeting the abnormal expression level of PTEN is anticipated to offer novel therapeutic avenues. Recently, noncoding RNAs (ncRNAs) have been reported to regulate protein expression, and it is definite that PTEN expression is controlled by ncRNAs epigenetically or posttranscriptionally as well. Herein, we provide a review on current understandings of the regulation of PTEN by ncRNAs, which could contribute to the development of novel approaches to the diseases with abnormal expression of PTEN.
\end{abstract}

Keywords: PTEN, Noncoding RNA, miRNA, IncRNA, Methylation, ceRNA

\section{Background}

Phosphatase and tensin homologue (PTEN), also named as MMAC1 (mutated in multiple advanced cancers), is located on chromosome 10q23.31 [1, 2]. PTEN encodes a 403-amino acid peptide, which is composed of a phosphatidylinositol-4,5-bisphosphate-binding domain (PBD) (residues 1-13), a catalytic phosphatase domain (PD) (residues 14-185), a C2 membrane binding domain (C2D)(residues 186-350), and a C-terminal tail (residues 351-403) [3, 4]. The PD includes a conserved catalytic motif HCKAGKGR, contributing to the dual lipid and protein phosphatase activity of PTEN $[4,5]$. The C2 domain includes two tyrosine phosphorylation sites (Y240 and Y315). The PDZ-binding domain (post-synaptic density protein (PSD95), Drosophila discs large (Dlg) and the tight junction protein zonula occludens-1 (ZO-1)) associates with the phosphatase activity, membrane association and stability of PTEN. There are two PDZ-binding domains and six phosphorylation sites in the C-terminal tail, including threonine 366 (Thr366), serine 370 (Ser370), Ser380, Thr382, Thr383 and Ser385 [6-11] (Fig. 1).

PTEN contributes to the control of several important cellular signaling pathways. PTEN dephosphorylates

\footnotetext{
* Correspondence: Ihuang@dmu.edu.cn

Department of Pathophysiology, College of Basic Medical Sciences, Dalian Medical University, Dalian, Liaoning 116044, People's Republic of China
}

phosphatidylinositol $(3,4,5)$-triphosphate (PIP3), therefore represses the activation of phosphatidylinositol-3-kinase (PI3K)/Akt and the mammalian target of rapamycin (mTOR) signaling pathway, Akt/ glycogen synthase kinase3(GSK-3)/Snail signaling pathway, or Akt/GSK-3/Wnt/ signaling pathway. Furthermore, GSK-3 interacts with and phosphorylates PTEN, which contributes to the inactivation of PTEN. Focal adhesion kinase (FAK) is dephosphorylated by PTEN directly, leading to the inactivation of FAK/p130Cas pathway. PTEN also dephosphorylates Src homology 2-containing protein (Shc) directly, and inhibits the activation of Shc/Raf/ERK1/2 (extracellular signal-regulated kinase) signaling cascade. Through controlling these pathways, PTEN ultimately represses cell survival, proliferation, metastasis and so on [12-18] (Fig. 2).

PTEN expression alteration is crucial to the pathogenesis of cancer and other diseases. Low level of PTEN caused by homozygous deletions, frameshift, nonsense mutations or hypermethylation of the gene or destability of the protein occurs frequently in various human cancers [19-23] and PTEN depletion in mice leads to a substantial rise in tumorigenesis [24, 25]. PTEN mutations were reported as a cause of obesity and autism spectrum disorders [26-28]. PTEN protein level was decreased in an OVA-induced-asthma mouse model, and the administration of PTEN expressing adenovirus remarkably reduced bronchial inflammation and airway hyperresponsiveness

(c) The Author(s). 2018 Open Access This article is distributed under the terms of the Creative Commons Attribution 4.0 International License (http://creativecommons.org/licenses/by/4.0/), which permits unrestricted use, distribution, and 


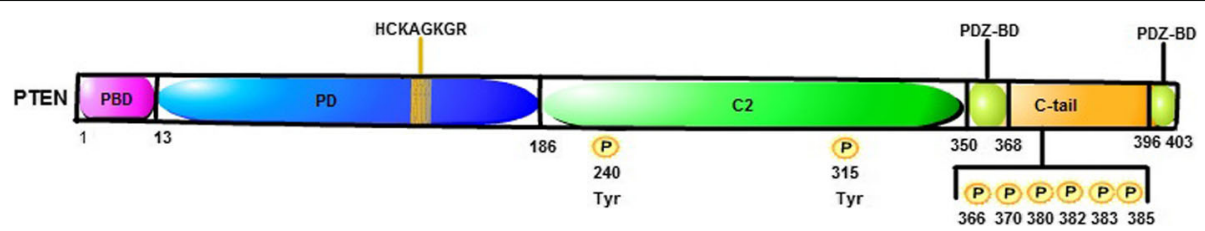

Fig. 1 The Structure of PTEN. PTEN encodes a 403-amino acid peptide, which is composed of a phosphatidylinositol-4, 5-bisphosphate-binding domain (PBD) (residues 1-13), a catalytic phosphatase domain (PD) (residues 14-185), a C2 membrane binding domain (C2D)(residues 186-350), and a C-terminal tail (residues 351-403). The PD includes a conserved catalytic motif HCKAGKGR. The C2 domain includes two tyrosine phosphorylation sites (Y240 and Y315). There are two PDZ-binding domains (PDZ-BD) and six phosphorylation sites in the C-terminal tail. PDZ, post-synaptic density protein (PSD95), Drosophila discs large (Dlg) and the tight junction protein zonula occludens-1 (ZO-1)

[29]. However, high level of PTEN either contributes to pathological processes. Elevated PTEN expression was observed in endothelium of atherosclerotic brachial arteries from hemodialysis patients. PTEN overexpression stimulated the thrombosis formation of arteriovenous graft by inducing endothelial dysfunction [30]. PTEN negatively regulates neuron survival, and PTEN downregulation showed neuroprotective effects in mouse models of neuron death and Parkinson's disease [31, 32]. Inhibition of PTEN rescued synaptic function and cognition in cellular and animal models of Alzheimer's disease, whereas
PTEN transgenic mice displayed synaptic depression [33]. In brief, abnormal PTEN expression level is associated to multiple diseases. Understanding the regulation mechanisms of PTEN expression and maintaining the homeostasis of PTEN should be beneficial.

The expression and activity of PTEN is modulated by several upstream molecules. P53 binds PTEN promoter and induces its transcription [34]. PDZK1 (PDZ-containing 1) induces PTEN dephosphorylation through binding the PDZ-binding domain in the PTEN C-terminal domain, which promotes the anti-oncogenic function of

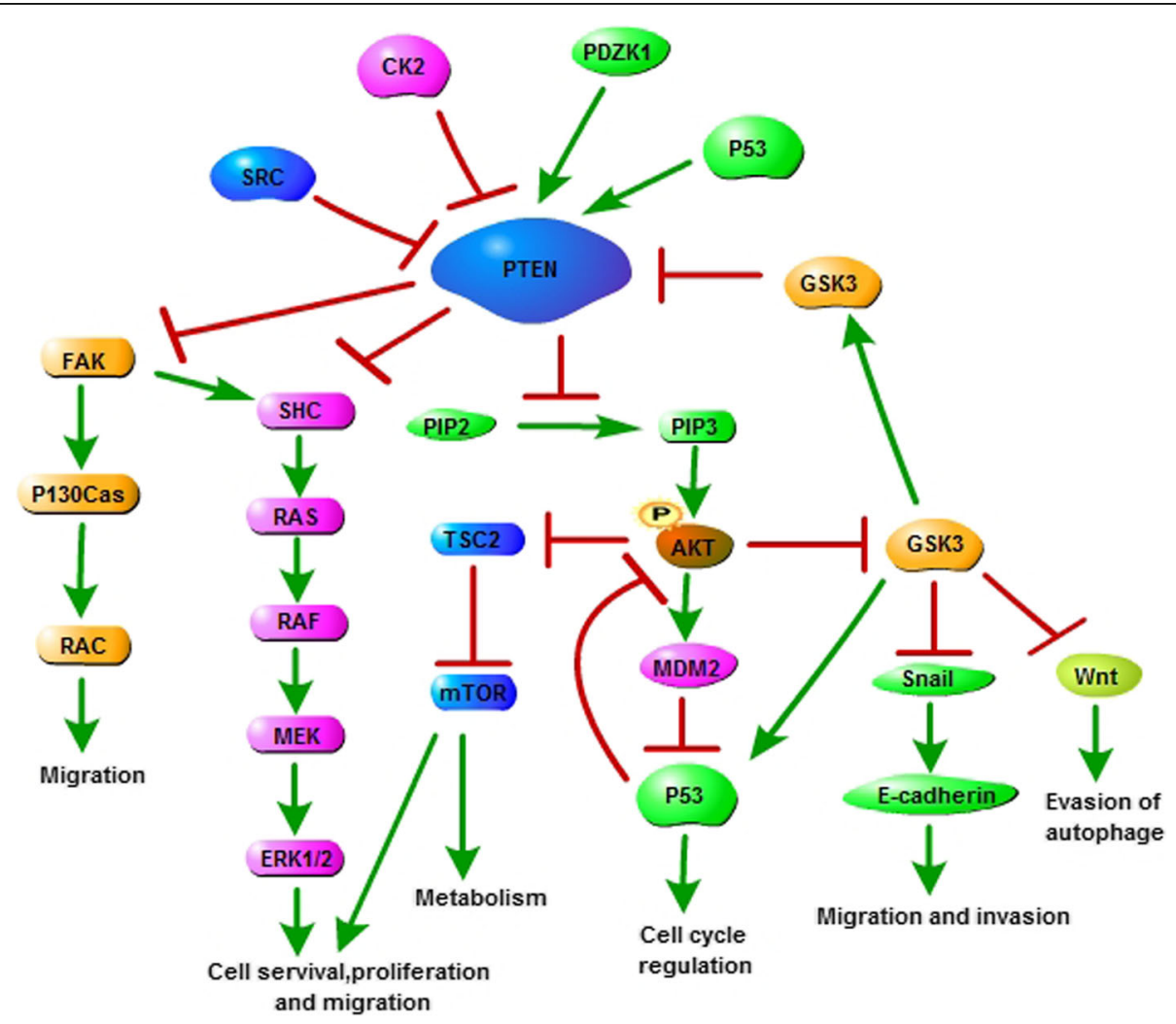

Fig. 2 The schematic representation of the major signaling pathways in which PTEN is involved. CK2, casein kinase Il; PDZK1, PDZ-containing 1; GSK3, Glycogen synthase kinase3; FAK, Focal adhesion kinase; Rac, Ras-related C3 botulinum toxin substrate; SHC, Src homology 2-containing protein; MEK, MAPKK(mitogen-activated protein kinase kinase); ERK1/2, Extracellular signal-related kinase 1/2; PIP3, Phosphatidylinositol (3,4,5)trisphosphate (Ptdlns $\left.(3,4,5) P_{3}\right)$; Akt, Protein kinase B (PKB); MDM2, Mouse double minute 2 homolog; TSC2, Tuberous Sclerosis Complex 2; mTORC, Mammalian target of rapamycin complex; CSCs, Cancer stem cells 
PTEN. Protein kinase CK2 (formerly casein kinase II) interacts with and phosphorylates PTEN C-terminal tail, which contributes to maintain PTEN stability [35]. Src inhibits PTEN activity to promote the post-ischaemic contractile recovery in apelin-induced cardioprotection [36]. Recently, with the development of the study on noncoding RNAs (ncRNAs), the control of PTEN expression by ncRNAs attracted more attention. Herein, we focus on the regulation of PTEN expression by ncRNAs, which is supposed to provide a reference for the coming laboratory and clinical studies on PTEN regulation (Fig. 3).

More than 98\% DNAs that do not encode proteins are called ncRNAs $[37,38]$. In general, ncRNAs are classified into two groups as small ncRNAs $(\leq 200 \mathrm{nt})$ and long ncRNAs (lncRNAs) (> $200 \mathrm{nt})$. MicroRNAs (miRNAs) ( 18 to $24 \mathrm{nt}$ ) are an important group of small ncRNAs, which epigenetically or posttranscriptionally control the expression of the target mRNAs by pairing to them, leading to the alteration of transcription, mRNA stability or translation [39-42]. LncRNAs take up a great proportion in the "transcriptome", which play vital gene regulatory roles in the chromatin modification, transcriptional regulation, posttranscriptional regulation and so on [43, 44]. Emerging evidence indicates that PTEN functions in a dosage-dependent manner during tumor development $[24,45]$. NcRNAs are key regulators of PTEN dosage, including miRNAs and IncRNAs, which delicately modulate the PTEN expression (Tables 1 and 2).

\section{MiRNAs modulate PTEN expression}

Altering PTEN expression by directly targeting PTEN mRNA MiR-21 is one of the first identified mammalian microRNAs. The human $m i R-21$ gene is located at chromosome 17q23.2 within a coding gene TMEM49 (also called vacuole membrane protein), which is highly conserved [46]. Early lineage tracing studies demonstrated that miR-21 was upregulated in various diseases, including acute pancreatitis [47], Myelodysplastic syndromes [48], severe steroid-insensitive allergic airway disease [49], liver cancer [50] and lung cancer [51].

PTEN is one of the important targets negatively regulated by miR-21. The 3'UTR of human PTEN contains a putative region that is able to pair to the seed sequence of miR-21 (Fig. 4). The exosomal miR-21 transferred from macrophages downregulated the PTEN level in gastric cancer cells, which resulted in the suppression of cell apoptosis and activation of PI3K/AKT signaling pathway [52]. Inhibition of miR-21 reversed EMT by increasing PTEN protein level in head and neck squamous cell carcinoma (HNSCC), resulting in the suppression of cell proliferation and motility [53]. MiR-21 was able to directly target the 3'UTR of PTEN, increasing clear-cell renal cell carcinoma (CCRCC) cell migration, invasion both in vitro and in vivo [54].

Expression of miR-130 family members has been recently reported to be correlated inversely to PTEN expression in bladder cancer, breast invasive carcinoma, lung adenocarcinoma and colon adenocarcinoma [55, 56]. Overexpression of miR-130a increased cell proliferation and motility via repression of PTEN expression, associated with the upregulation of FAK and Akt phosphorylation [55-57]. MiR-130a decreases the PTEN level to activate PI3K/Akt/eNOS (endothelial nitric oxide synthase) signaling pathway, promoting human coronary artery endothelial cells (HCAECs) injury and inflammatory responses [57]. Exogenous expression of

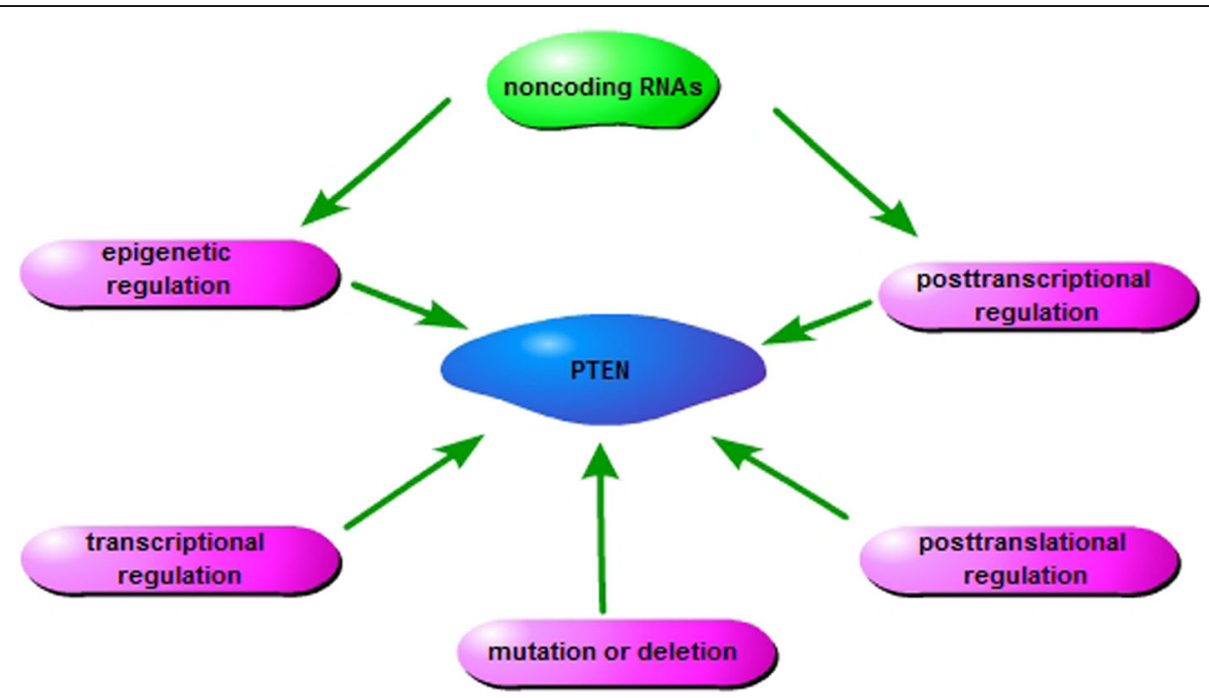

Fig. 3 The regulation of PTEN expression. PTEN expression is dynamically regulated by various events, including genomic mutation or deletion, transcriptional, epigenetic, posttranscriptional, and posttranslational modulation. Noncoding RNAs epigenetically or posttranscriptionally regulate PTEN expression 
Table 1 Regulation of PTEN expression by miRNAs

\begin{tabular}{|c|c|c|c|c|}
\hline MiRNA & $\begin{array}{l}\text { PTEN } \\
\text { expression }\end{array}$ & Mechanism & Disease & Reference \\
\hline miR-21 & Down & directly targeting PTEN mRNA & Gastric cancer, HNSCC, CCRCC & [52-54] \\
\hline $\operatorname{miR}-130$ & Down & directly targeting PTEN mRNA & $\begin{array}{l}\text { Bladder cancer, Breast invasive carcinoma, } \\
\text { HCAECs injury, Inflammatory responses, PD, } \\
\text { Lung adenocarcinoma, Colon adenocarcinoma }\end{array}$ & {$[55-58]$} \\
\hline $\operatorname{miR}-130$ & Up & directly targeting PTEN mRNA & NSCLC & [59] \\
\hline miR-451 & Up & directly targeting PTEN mRNA & Lung cancer, Ovarian cancer & {$[60,61]$} \\
\hline $\operatorname{miR}-221 / 222$ & Down & directly targeting PTEN mRNA & NSCLC,HCC, TRAIL-induced cell death & [62] \\
\hline miR-301a & Down & directly targeting PTEN mRNA & $\begin{array}{l}\text { Breast cancer, Neuronal death, Ewing's carcoma, } \\
\text { Melanoma, Insulin resistance }\end{array}$ & {$[63-67]$} \\
\hline $\operatorname{miR}-214$ & Down & directly targeting PTEN mRNA & Tumorigenesis, Immunology, Cardiac injury & {$[68-71]$} \\
\hline miR-494 & Down & directly targeting PTEN mRNA & Ischemia/Reperfusion -induced myocardial injury & {$[72,73]$} \\
\hline $\begin{array}{l}\text { miR-155-5p/130b/ } \\
616 / 19 / 92 a / 10 a / \\
106 a / 429 / 26 a / 486-5 p\end{array}$ & Down & directly targeting PTEN mRNA & $\begin{array}{l}\text { HCC, NSCLC, Breast cancer, Lung cancer, } \\
\text { Colorectal Cancer, Chronic myeloid leukemia, } \\
\text { Intestinal cancer, Acute T-cell lymphoblastic leukemia }\end{array}$ & [74-84] \\
\hline miR-29 & Up & $\begin{array}{l}\text { inducing the hypomethylation of PTEN } \\
\text { promoter by inhibiting DNMT1, DNMT3b } \\
\text { and SET1A expression }\end{array}$ & Liver fibrosis & {$[87,88]$} \\
\hline miR-101 & Up & $\begin{array}{l}\text { inducing the hypomethylation of PTEN } \\
\text { promoter by inhibiting DNMT3A expression }\end{array}$ & Lung cancer & {$[89,90]$} \\
\hline miR-185 & Up & $\begin{array}{l}\text { inducing the hypomethylation of PTEN } \\
\text { promoter by inhibiting DNMT1 expression }\end{array}$ & $\mathrm{HCC}$ & [91] \\
\hline
\end{tabular}

miR-130a prevented midbrain dopaminergic (mDA) neuron degeneration in Parkinson's disease (PD) by suppressing the synthesis of PTEN [58].

Controversially, miR-130 was also found to be downregulated and positively correlated to PTEN levels in non-small cell lung cancer (NSCLC) tissue samples. The upregulation of miR-130 significantly increased PTEN expression, inhibited NSCLC cell growth and enhanced cell apoptosis both in vitro and in vivo [59]. Even the same pairing sequence of miR-130 and PTEN 3'UTR were used, opposite results were obtained in dual luciferase reporter assays from two reports. The relative activity of the luciferase harboring PTEN 3'UTR was promoted in A549 cells but repressed in $293 \mathrm{~T}$ cells by miR-130 [56, 59]. Although the mechanisms remain obscure, a tissue-specific pattern is possible for the regulation of PTEN by miR-130. MiR-130 might regulate PTEN expression through different ways according to the cellular context. PTEN protein was found to be slightly increased after the pre-miR-451-transfection in lung cancer cells [60]. Both miR-451 and PTEN expression level was reported to be significantly reduced in ovarian cancer [61].

Over the past decade, mountains of results show that the interaction of PTEN with miRNAs related to different diseases. MiR-221 and miR-222 were reported to be upregulated in aggressive NSCLC and hepatocarcinoma (HCC) cells, and conferred resistance to TNF-related apoptosis-inducing ligand (TRAIL)-induced cell death by targeting PTEN [62]. MiR-301a mediates the tumorigenesis of breast cancer, Ewing's carcoma and melanoma, prevents neuronal death, and contributes to insulin resistance via decreasing PTEN protein level [63-67]. MiR-214 induces tumorigenesis, stimulates immunology, and protects cardiac injury through inhibiting PTEN expression [6871]. MiR-494 targets PTEN and activates Akt pathway, leading to protect against ischemia/reperfusion -induced myocardial injury $[72,73]$. There are also many other miRNAs directly targeting PTEN, such as miR-155-5p [74], miR-130b [75], miR-616 [76], miR-19 [77], miR-92a [78], miR-10a [79], miR-106a [80], miR-429 [81], miR-26a $[82,83]$ and miR-486-5p [84]. Consistent with miR-21, these miRNAs directly bind to the 3'UTR of human PTEN, and inhibit PTEN expression.

\section{Upregulating PTEN expression by targeting DNA methyltransferases (DNMTs)}

DNA methyltransferases (DNMTs) are the enzymes for DNA methylation, transferring a methyl group to the cytosine residues of DNA. DNA methylation of a gene promoter typically represses the gene transcription. The promoter region of the PTEN gene consists of three methylation sites. Overexpression of DNMT1 led to PTEN downregulation due to the CpG island methylation in promoter, which promoted tumorigenesis of breast cancer, ovarian cancer and acute myeloid leukemia (AML) $[85,86]$. MiRNAs targeting DNMTs increase the PTEN expression. MiR-29a was found to 
Table 2 Regulation of PTEN expression by IncRNAs

\begin{tabular}{|c|c|c|c|c|c|}
\hline LncRNA & PTEN expression & Mechanism & MiRNA & Disease & Reference \\
\hline PTENP1 & Up & acting as ceRNAs & $\begin{array}{l}\text { miR-21, miR-17, miR-214, } \\
\text { miR-19, miR-20, miR-93, } \\
\text { miR-106b, miR-26 }\end{array}$ & $\begin{array}{l}\text { CCRCC, OSCC, HCC, } \\
\text { Gastric cancer }\end{array}$ & {$[54,96-101]$} \\
\hline HOTAIR & Up & acting as ceRNAs & miR-19 & Cardiac hypertrophy & {$[105]$} \\
\hline Linc-USP16 & Up & acting as ceRNAs & miR-21, miR-590-5p & $\mathrm{HCC}$ & {$[106]$} \\
\hline LncRNA-BGL3 & Up & acting as ceRNAs & $\begin{array}{l}\text { miR-17, miR-20a, miR-20b, } \\
\text { miR-93, miR-106a }\end{array}$ & Chronic myeloid leukemia & {$[80]$} \\
\hline CASC2 & Up & $\begin{array}{l}\text { acting as both ceRNAs } \\
\text { and downregulators of miRNAs }\end{array}$ & miR-21, miR-181a & $\begin{array}{l}\text { Osteosarcoma, Glioma, } \\
\text { Cervical cancer }\end{array}$ & [107-109] \\
\hline MEG3 & Up & $\begin{array}{l}\text { acting as both ceRNAs } \\
\text { and downregulators of miRNAs }\end{array}$ & miR-1297, miR-19a, miR-21 & Breast cancer, Glioma, CAD & [111-113] \\
\hline IncRNA GAS5 & Up & $\begin{array}{l}\text { acting as both ceRNAs } \\
\text { and downregulators of miRNAs }\end{array}$ & $\begin{array}{l}\text { miR-21, miR-103, miR-196a, } \\
\text { miR-205, miR-32-5p }\end{array}$ & $\begin{array}{l}\text { HER2-positive breast cancer, } \\
\text { HCC, NSCLC, Cardiac fibrosis, } \\
\text { Endometrial cancer, Cervical cancer, } \\
\text { Pancreatic cancer }\end{array}$ & [114-120] \\
\hline XIST & Up & $\begin{array}{l}\text { acting as both ceRNAs } \\
\text { and downregulators of miRNAs }\end{array}$ & miR-181a, MiR-494 & HCC, Spinal Cord Injury & {$[121,122]$} \\
\hline NBAT1 & Up & $\begin{array}{l}\text { acting as both ceRNAs } \\
\text { and downregulators of miRNAs }\end{array}$ & $\operatorname{miR}-21$ & Osteosarcoma & {$[123]$} \\
\hline Inc-2/Inc-6 & Up & $\begin{array}{l}\text { acting as both ceRNAs } \\
\text { and downregulators of miRNAs }\end{array}$ & miR-26a & Prostate cancer, Glioma & {$[126,127]$} \\
\hline FER1L4 & Up & $\begin{array}{l}\text { acting as both ceRNAs } \\
\text { and downregulators of miRNAs }\end{array}$ & miR-106a-5p & Colon cancer, Gastric cancer & {$[130,131]$} \\
\hline lincRNA-p21 & Up & $\begin{array}{l}\text { acting as both ceRNAs } \\
\text { and downregulators of miRNAs }\end{array}$ & miR-181b & Liver fibrosis & [132] \\
\hline PTENP1 asRNA $\beta$ & Up & $\begin{array}{l}\text { increasing the stability } \\
\text { and miRNA sponge activity } \\
\text { of PTENP1 }\end{array}$ & - & - & [133] \\
\hline HOTAIR & Down & $\begin{array}{l}\text { enhancing PTEN methylation } \\
\text { via miRNA sponging }\end{array}$ & miR-29b & Liver Fibrosis, LSCC & {$[134,135]$} \\
\hline PTENP1 asRNA a & Down & $\begin{array}{l}\text { enhancing PTEN methylation } \\
\text { via the recruitment of DNMT3a } \\
\text { and EZH2 }\end{array}$ & - & - & [133] \\
\hline
\end{tabular}

inhibit DNMT1, DNMT3b and SET domain containing 1A (SET1A) expression, resulting in elevated PTEN expression and decreased offibrogenic activities in hepatic stellate cells (HSCs) [87]. Curcumin treatment suppressed liver fibrosis by inducing miR-29b expression in HSCs, which led to the low expression of DNMT3b and PTEN hypomethylation [88] (Fig. 5). Bioinformatics and dual luciferase reporter assays demonstrated that DNMT3A is a target of miR-101 [89]. Introduction of miR-101 inhibitor increased the protein level of DNMT3A instead of the mRNA expression. Overexpression of miR-101 or silencing of DNMT3A induced the hypomethylation of PTEN promoter which was verified by a methylation specific PCR assay [90]. The expression of miR-185 was inhibited in cultured human HCC cells [91]. Introduction of miR-185 mimics significantly reduced DNMT1 expression, decreased PTEN promoter methylation and increased the protein level of PTEN. MiR-185 overexpression decreased the reporter activity of the luciferase with DNMT1 3'UTR, and forced expression of DNMT1 reversed the loss of PTEN promoter methylation mediated by miR- 185 .

\section{LncRNAs modulate PTEN expression indirectly}

LncRNAs have multiple important functions in cellular and developmental processes. LncRNAs may carry out

\section{PTEN 3'-UTR 5'......UAGUACUCUgGUUgUUAAGCUAG.......3' hsa-miR-21 3'......AGUUGUAGUCAGACUAUUCGAUG......5'}

Fig. 4 A Predicted miR-21 binding site within the 3'UTR of PTEN mRNA. By Target Scan Human Release 7.0 (http://www.targetscan.org) 


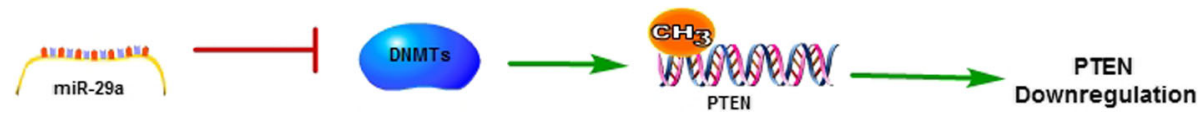

Fig. 5 MiR-29a upregulates PTEN expression by targeting DNMTs. MiR-29a could repress DNMTs at posttranscriptional level, resulting in a decrease of $\mathrm{CpG}$ island methylation of the PTEN promoter. DNMTs, DNA methyltransferases

both gene inhibition and activation through diverse mechanisms $[43,44]$. The studies on the lncRNAs associated with PTEN suggest that lncRNAs modulate PTEN expression by altering either the related miRNAs or promoter methylation.

\section{Acting as competing endogenous RNAs (ceRNAs)} LncRNAs can act as competing endogenous RNAs (ceRNAs) to indirectly regulate mRNAs through the shared miRNAs. LncRNAs compete the seed sites of miRNAs with their target mRNAs, leading to block the effects of miRNAs on the mRNA targets [92-95].

PTENP1, located on chromosome 9p21, is a highly conserved pseudogene of PTEN. Gan Yu et al. reported the low expression of PTENP1 due to methylation in CCRCC tissues and cell lines. Both PTEN and PTENP1 expression is inversely correlated with miR-21 expression. In miR-21 overexpressing cells, PTENP1 introduction suppressed cell proliferation and metastasis, and increased the cell sensitivity to cisplatin and gemcitabine, restoring the phenotypes induced by PTEN in vitro and in vivo [54]. Activation of PTENP1 partially inhibited the suppression of PTEN by miR-21 in oral squamous cell carcinoma (OSCC) tumor xenografts [96]. Evidences have revealed that PTENP1 expression level is positively related to PTEN transcript, and PTENP1 protects PTEN mRNA through serving as a decoy for miRNAs, such as miR-21, miR-17, miR-214, miR-19, miR-20, miR-93, miR-106b and miR-26 families [5, 54, 97-101] (Fig. 6).

Homeobox (HOX) transcript antisense RNA (HOTAIR) is encoded within the HoxC gene cluster on chromosome 12, which silences the expression of HoxD genes and numerous tumor and metastasis suppressors [102, 103] by interacting with chromatin-remodeling enzymes [104]. On the contrary, HOTAIR regulates PTEN expression as a ceRNA. HOTAIR expression decreased notably in sustained cardiac hypertrophy mouse models, in which miR-19 expression was increased and inversely correlated with HOTAIR expression. HOTAIR has a binding site for miR-19 seed sequence, and HOTAIR overexpression

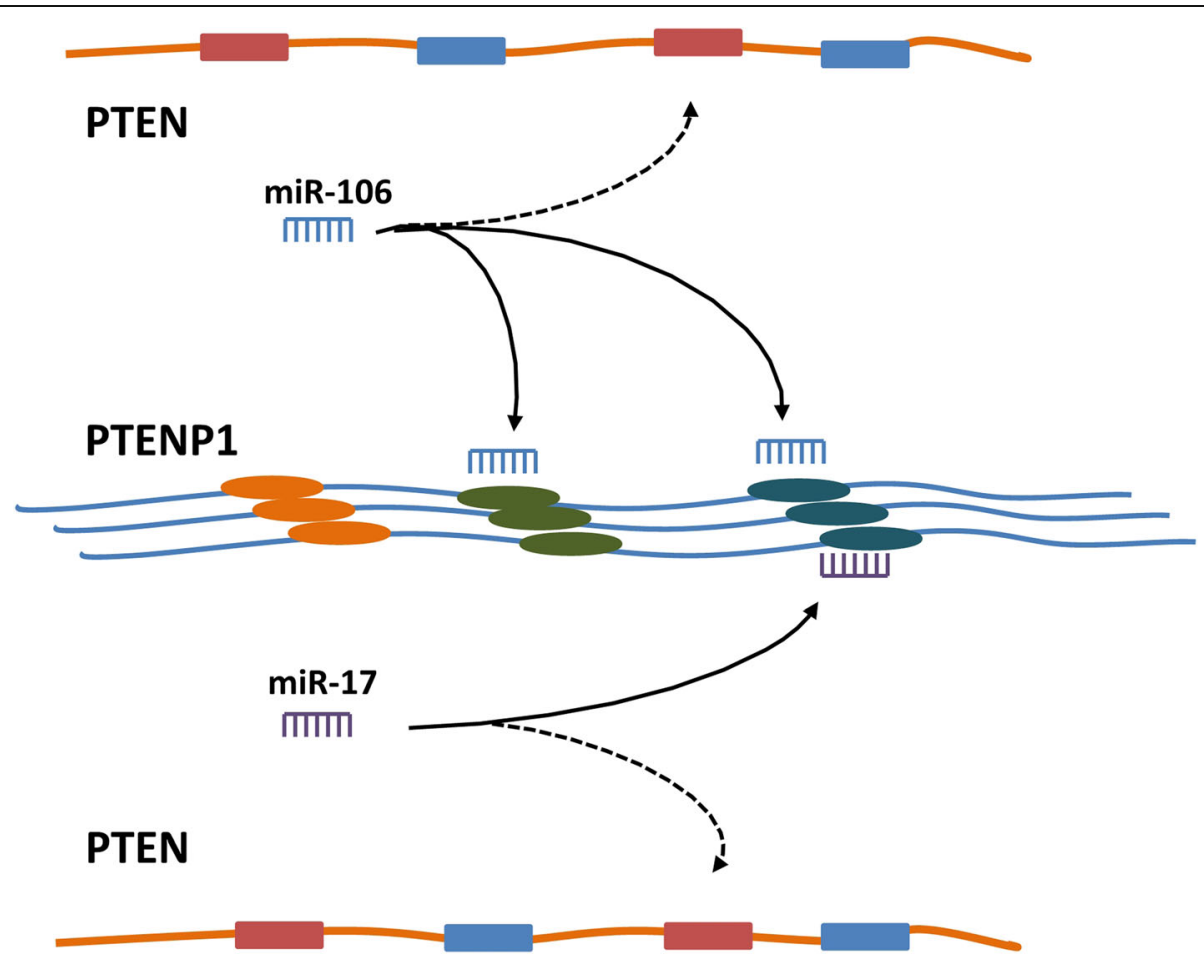

Fig. 6 PTENP1 works as a ceRNA to promote PTEN expression. PTENP1 recruits miRNAs such as miR-181a and miR-21, therefore impairs the miRNAs binding PTEN 
restored the inhibition of luciferase activity with PTEN 3'UTR mediated by miR-19 [105].

Linc-USP16 acted as a ceRNA for miR-21 and miR-590-5p, promoting PTEN expression to repress the growth and stimulate apoptosis in $\mathrm{HCC}$ in vivo and in vitro [106]. LncRNA-BGL3 worked as a ceRNA for miR-17, miR-93, miR-20a, miR-20b, miR-106a and miR-106b, rescuing the repression of PTEN expression to inhibit Bcr-Abl-induced cellular transformation [80].

\section{Acting as both ceRNAs and downregulators of miRNAs}

LncRNAs can also decrease the expression level of miRNA as well as being sponges, leading to suppress the effects of miRNAs on their mRNA targets.

Cancer susceptibility candidate 2 (CASC2), mapped to chromosome 10q26, encodes a lncRNA which acts as a ceRNA of miR-21 or miR-181a and exerts biological effects by increasing the expression of PTEN [107, 108]. The expression of CASC2 is significantly downregulated in glioma, osteosarcoma or cervical cancer tissues and cell lines, and CASC2 expression level is negatively correlated to miR-181a level in glioma tissues. CASC2 overexpression significantly repressed cell proliferation, and amplified temozolomide- or cisplatin-induced repression of cell proliferation in vitro, which was associated with the downregulation of miR-181a and miR-21. CASC2 overexpression upregulated PTEN level, which was partially restored by miR-181a and miR-21 mimics. In addition, CASC2 was found to interact directly with miR-181a and miR-21 in dual-luciferase reporter assays [108, 109].

Maternally expressed gene 3 (MEG3), encoding a lncRNA, is located at the chromosome 14q32. In testicular germ cell tumor (TGCT) tissues, lncRNA MEG3 level is significantly decreased, while PTEN protein but not mRNA levels are notably downregulated [110]. Bioinformatics analyses showed that miR-1297 bound not only 3'UTR of PTEN mRNA but also MEG3 [111]. MEG3 overexpression disturbed the binding of miR-1297 to 3'UTR of PTEN mRNA and remitted the reduction of PTEN induced by miR-1297. MEG3 downregulation and miR-19a upregulation were reported in malignant glioma tissues and cell lines, and luciferase results verified the complementary binding between miR-19a and MEG3. MiR-19a overexpression repressed the expression of PTEN and promoted glioma cell proliferation, migration, and invasion [112]. Moreover, in the coronary artery disease (CAD) tissues, MEG3 level declines, and miR-21 expression has negative correlation with MEG3 expression. Overexpression of MEG3 suppressed miR-21 expression, promoted the expression of PTEN, and suppressed the proliferation of endothelial cells [113].

LncRNA growth arrest specific transcript 5 (lncRNA GAS5) is downregulated in NSCLC, breast cancer and HCC tissues, and lncRNA GAS5 knockdown repressed cell viability. lncRNA GAS5 competes with PTEN to bind miR-21, and depletion or overexpression of lncRNA GAS5 could increase or decrease miR-21 expression, resulting in the downregulation or upregulation of PTEN level in these tumor cells [114-116]. A low expression of lncRNA GAS5 and an upregulation of miR-21 are reported in cardiac fibrosis. The downregulation of PTEN expression mediated by miR-21 mimics was reversed by overexpressing lncRNA GAS5 in cardiac fibroblast cells [117]. LncRNA GAS5 could also induce PTEN expression by inhibiting miR-103 [118], miR-196a and miR-205 [119], and miR-32-5p [120].

The lncRNA X inactivate-specific transcript (XIST) directly interacts with miR-181a, and they repress the expression of each other. XIST overexpression restored the PTEN downregulation induced by miR-181a mimics, and transfection with XIST siRNA significantly enhanced the proliferation and invasion of liver cancer cells together with a decreased PTEN level [121]. Neuronal apoptosis and lncRNA XIST expression level were found to be promoted in an spinal cord injury model. XIST acts as a sink for miR-494, leading to derepression of PTEN. MiR-494 expression was upregulated with XIST knockdown, whereas was downregulated with XIST overexpression. AntagomiR-494 treatment reversed the protective effects of XIST depletion on spinal cord injury through blocking the PTEN/PI3K/AKT signaling pathway [122].

The low expression of LncRNA neuroblastoma associated transcript 1 (NBAT1) in osteosarcoma tissues and cells was closely correlated to clinical stages, lymph node metastasis and poor prognosis [123]. NBAT1 binds miR-21, and suppresses miR-21 expression. NBAT1 overexpression downregulated osteosarcoma growth and metastasis via acting as a ceRNA against miR-21, which was associated with PTEN upregulation in vitro and in vivo.

The expression of lnc-2 and lnc- 6 showed positive correlation with PTEN in prostate cancer cohorts [124, 125]. Knockdown of lnc-2 or lnc-6 led to a significant decrease in PTEN expression at both protein and mRNA levels and a significant increase in cell proliferation. On the contrary, depletion of PTEN reduced the expression of both lnc- 2 and lnc-6, and the reduction of PTEN expression by overexpressing known PTEN-regulating miRNAs could be rescued by overexpressing lnc-2 sub-sequences [126]. PTEN and lnc- 6 are downregulated while miR-26a is upregulated in human glioma. Lnc-6 introduction into glioma cells resulted in a decrease of miR-26a expression [127].

Microarray and real time PCR results showed that lncRNA fer-1-like family member 4 (FER1L4) was downregulated in gastric cancer, endometrial carcinoma and colon cancer tissues or cell lines [128]. Enforced expression of FER1L4 increased PTEN expression at both mRNA and protein levels, which might contribute to cell 
cycle arrest and apoptosis [129]. In colon cancer cell lines, FER1L4 expression is inversely correlated with miR-106a-5p expression [130]. Luciferase assay results suggested direct interactions between miR-106a-5p and FER1L4 or PTEN. Knockdown of FER1L4 increased miR-106a-5p expression level and decreased the levels of PTEN mRNA and protein $[130,131]$.

Fujun $\mathrm{Yu}$ et al. reported a novel lincRNA-p21-miR181b-PTEN signaling cascade in liver fibrosis [132]. LincRNA-p21 overexpression significantly suppressed the isolated rat HSC activation and the expression of extracellular matrix (ECM) proteins, which was reversed by depletion of PTEN. MiR-181b binds lincRNA-p21, and miR-181b level was reduced by exogenous lincRNA-p21, while the effects of lincRNA-p21 on PTEN expression and HSC activation were inhibited by miR-181b mimics.

\section{Increasing the stability of IncRNAs}

PTENP1, also encodes antisense RNAs (asRNAs), which has two isoforms, $\alpha$ and $\beta$. PTENP1 asRNA $\beta$ interacts with PTENP1 through an RNA:RNA pairing interaction, and the stability of PTENP1 was decreased when the interaction was interfering using U6 encoded ssRNAs or PTENP1 asRNA $\beta$ was knocked down. Thus PTENP1 asRNA $\beta$ upregualtes PTEN level via increasing the stability and miRNA sponge activity of PTENP1 [133].

\section{Prompting the methylation of PTEN promoter}

HOTAIR expression is upregulated in HSCs during liver fibrosis. HOTAIR knockdown suppressed HSC proliferation and activation in vitro and in vivo, increasing PTEN level, with the loss of DNA methylation mediated by miR-29b [134]. HOTAIR levels were significantly higher in human laryngeal squamous cell cancer (LSCC), and bisulfite sequencing of the PTEN promoter addressed that PTEN CpG islands were unmethylated in HOTAIR siRNA-transduced cells and PTEN methylation was significantly reduced [135]. Collectively, HOTAIR might contribute to PTEN promoter methylation via sponging miR-29b.

The expression of PTEN and PTENP1 asRNA $\alpha$ is negatively correlated in cell lines, and the $\alpha$ depletion resulted in the increase of PTEN transcript. PTENP1 asRNA $\alpha$ binds the PTEN promoter, and epigenetically downregulates PTEN transcription by the recruitment of DNMT3a and Enhancer of zeste homolog 2 (EZH2) to enhance the methylation of PTEN promoter. PTENP1 asRNA $\alpha$ knockdown induces cell cycle arrest and sensitizes cells to doxorubicin, suggesting the biological function for the PTENP1 asRNAs [133, 136].

\section{Conclusions and future directions}

Due to the essential physiological function of PTEN, the ncRNAs controlling PTEN expression play crucial roles in various biological activation, such as autophagy and cell stemness. PTEN induces autophagy through repressing PI3K/Akt pathway, while miR-21 elevation was found in human degenerative nucleus pulposus tissues, which inhibits autophagy and induces ECM degradation via repressing PTEN expression [137]; Human aortic smooth muscle cell-derived exosomal miR-221/222 suppressed the autophagy in human umbilical vein endothelial cells by regulating PTEN/Akt signaling pathway in a co-culture system [138]; MiR-21-5p significantly increases cell stemness of keloid keratinocytes, mediated by PTEN repression and AKT activation, which may account for the invasion and recurrence of keloids [139]. MiR-10b promotes cellular self-renewal and expression of stemness markers in breast cancer stem cells through negative regulation of PTEN and sustained activation of AKT [140].

Actually, therapeutic strategies for multiple diseases focus on PI3K/Akt pathway inhibitors. However, the therapeutic benefit is modest due to the network complexities [141, 142]. PTEN modulation has been considered as a possible approach to tumor and other diseases. NcRNAs including lncRNAs and miRNAs act alone or interact with each other to regulate PTEN expression. Elucidation of the details that ncRNAs modulate PTEN expression may provide novel insights into the regulation network of PTEN, which could suggest possible strategies to target PI3K/Akt pathway.

Primary therapeutic attempts targeting ncRNAs to alter the PTEN expression have shown effects. Sophocarpine, a tetracyclic quinolizidine alkaloid derived from Sophora alopecuroides $L$, has shown inhibitory effects on HNSCC progression via the downregulation of miR-21 and the upregulation of PTEN in vivo and in vitro [53]. Ursolic acid exerted protective action on high glucose-induced cell podocyte injury via decreasing miR-21 expression, which resulted in an increase of PTEN level [143]. Combination of STAT3 inhibitor and DDP treatment led to a notable reduction of STAT3/ miR-21 axis and an increase of PTEN level, repressing oral squamous cell carcinoma (OSCC) cell proliferation, migration and invasion [144].

As-miR-21 treatment presented an obvious inhibition on established glioma tumor growth and an increase in PTEN expresson. Coincidently, in a prostate xenograft model, injection of as-miR-4534 led to a significant reduction in tumor volume, which increased the expression level of PTEN [145]. In a spontaneously developed lung tumors mouse model, treatment with the miR-214 antisense oligonucleotides microvesicles displayed promotion of PTEN levels and reduction of growth of spontaneous lung tumors [68]. Furthermore, administration of LNA-antimiR-19a increased the sensitivity of multidrug resistant MCF-7 cells to Taxol in vivo, with an upregulation of PTEN verified [146]. The growth of human 
LSCC xenograft was remarkably inhibited by HOTAIR shRNA lentivirus treatment [135], and injection of the PTENP1-expressing baculovirus effectively mitigated the HCC xenograft tumor growth, which was associated with the increase of PTEN [97].

In term of the importance of PTEN expression level in physiological situation and pathogenesis of various diseases, modulating PTEN level could be considered as potential approaches for multiple diseases, while clarifying the regulation network of PTEN including ncRNAs is predicted to be able to provide novel strategies.

\begin{abstract}
Abbreviations
AML: Myeloid leukemia; C2D: C2 membrane binding domain; CAD: Coronary artery disease; CASC2: Cancer susceptibility candidate 2; CCRCC: Clear-cell renal cell carcinoma; ceRNAs: Competing endogenous RNAs; CK2: Formerly casein kinase II; CSCs: Cancer stem cells; DNMTs: DNA methyltransferases; ECM: Extracellular matrix; EMT: Mesenchymal transition; eNOS: Endothelial nitric oxide synthase (eNOS); ERK1/2: Extracellular signal-regulated kinase; FAK: Focal adhesion kinase; FER1L4: IncRNA fer-1-like family member 4; GSK3: Glycogen synthase kinase3; HCAECs: Human coronary artery endothelial cells; HNSCC: Head and neck squamous cell carcinoma; HOTAIR: Homeobox (HOX) transcript antisense RNA; HSC: Hepatic stellate cell; IncRNA GAS5: IncRNA growth arrest specific transcript 5; IncRNAs: Long ncRNAs; LSCC: Laryngeal squamous cell cancer; mDA: Midbrain dopaminergic; Meg3: Maternally expressed gene 3; miRNAs: Small ncRNAs; MMAC1: Mutated in multiple advanced cancers; mTORC: Mammalian target of rapamycin complex; NBAT1: LncRNA neuroblastoma associated transcript 1; ncRNAs: Noncoding RNAs; NSCLC: Non-small cell lung cancer; OSCC: Oral squamous cell carcinoma; PBD: Phosphatidylinositol-4,5-bisphosphate-binding domain; PD: A catalytic domain phosphatase domain; PD: Parkinson's disease; PDZ: Post-synaptic density protein (PSD95), Drosophila discs large (Dlg) and the tight junction protein zonula occludens-1 (ZO-1); PDZK1: PDZ-containing 1;

PI3K: Phosphatidylinositol 3-kinase; PIP3: Phosphatidylinositol (3,4,5)-triphosphate; PTEN: Phosphatase and tensin homologue; PTENP1: Pseudogene of PTEN; SET1A: SET domain containing 1A; Shc: Src homology 2-containing protein; TGCT: Testicular germ cell tumor; TRAlL: TNF-related apoptosis-inducing ligand; TSC2: Tuberous Sclerosis Complex 2; XIST: IncRNA X inactivate-specific transcript
\end{abstract}

\section{Acknowledgements}

This work was supported by Liaoning Provincial program for Top Discipline of Basic Medical Sciences. We thank all the members of Huang lab for kind support.

\section{Funding}

This work was supported by the Climbing Scholars Supporting Program of Liaoning; and National Natural Science Foundation of China (81772971).

\section{Authors' contributions}

WL and LH designed and wrote the paper; WL, TZ, LG and LH collected and read the references, and made the figures. All authors read and approved the final manuscript.

\section{Ethics approval and consent to participate}

Not applicable.

\section{Consent for publication}

Not applicable.

\section{Competing interests}

The authors declare that they have no competing interests.

\section{Publisher's Note}

Springer Nature remains neutral with regard to jurisdictional claims in published maps and institutional affiliations.
Received: 26 June 2018 Accepted: 1 September 2018

Published online: 10 September 2018

\section{References}

1. Steck PA, Pershouse MA, Jasser SA, Yung WK, Lin H, Ligon AH, et al. Identification of a candidate tumour suppressor gene, MMAC1, at chromosome 10q23.3 that is mutated in multiple advanced cancers. Nat Genet. 1997;15(4):356-62.

2. Shinde SR, Maddika S. PTEN regulates glucose transporter recycling by impairing SNX27 Retromer assembly. Cell Rep. 2017;21(6):1655-66.

3. Caserta E, Egriboz O, Wang H, Martin C, Koivisto C, Pecot T, et al. Noncatalytic PTEN missense mutation predisposes to organ-selective cancer development in vivo. Genes Dev. 2015;29(16):1707-20.

4. Kim DH, Suh J, Surh YJ, Na HK. Regulation of the tumor suppressor PTEN by natural anticancer compounds. Ann N Y Acad Sci. 2017;1401(1):136-49.

5. Uversky VN, Dave V, lakoucheva LM, Malaney P, Metallo SJ, Pathak RR, et al. Pathological unfoldomics of uncontrolled chaos: intrinsically disordered proteins and human diseases. Chem Rev. 2014;114(13):6844-79.

6. Lee JO, Yang H, Georgescu MM, Di Cristofano A, Maehama T, Shi Y, et al. Crystal structure of the PTEN tumor suppressor: implications for its phosphoinositide phosphatase activity and membrane association. Cell. 1999:99(3):323-34.

7. Salmena L, Carracedo A, Pandolfi PP. Tenets of PTEN tumor suppression. Cell. 2008;133(3):403-14.

8. Shnitsar I, Bashkurov M, Masson GR, Ogunjimi AA, Mosessian S, Cabeza EA, et al. PTEN regulates cilia through Dishevelled. Nat Commun. 2015;6:8388.

9. Adey NB, Huang L, Ormonde PA, Baumgard ML, Pero R, Byreddy DV, et al. Threonine phosphorylation of the MMAC1/PTEN PDZ binding domain both inhibits and stimulates PDZ binding. Cancer Res. 2000;60(1):35-7.

10. Meiling-Wesse K, Epple UD, Krick R, Barth H, Appelles A, Voss C, et al. Trs85 (Gsg1), a component of the TRAPP complexes, is required for the organization of the preautophagosomal structure during selective autophagy via the Cvt pathway. J Biol Chem. 2005;280(39):33669-78.

11. Valiente M, Andrés-Pons A, Gomar B, Torres J, Gil A, Tapparel C, et al. Binding of PTEN to specific PDZ domains contributes to PTEN protein stability and phosphorylation by microtubule-associated serine/threonine kinases. J Biol Chem. 2005;280(32):28936-43.

12. Cherniack AD, Shen H, Walter V, Stewart C, Murray BA, Bowlby R, et al. Integrated molecular characterization of uterine Carcinosarcoma. Cancer Cell. 2017;31(3):411-23.

13. Gemmill RM, Nasarre P, Nair-Menon J, Cappuzzo F, Landi L, D'Incecco A, et al. The neuropilin 2 isoform NRP2b uniquely supports TGF beta-mediated progression in lung cancer. Science Signaling. 2017;10(462):eaag0528.

14. Xu J, Liu D, Niu H, Zhu G, Xu Y, Ye D, et al. Resveratrol reverses doxorubicin resistance by inhibiting epithelial-mesenchymal transition (EMT) through modulating PTEN/Akt signaling pathway in gastric cancer. J Exp Clin Cancer Res. 2017;36(1):19.

15. Cavazzoni A, La Monica S, Alfieri R, Ravelli A, Van Der Steen N, Sciarrillo R, et al. Enhanced efficacy of AKT and FAK kinase combined inhibition in squamous cell lung carcinomas with stable reduction in PTEN. Oncotarget. 2017;8(32):53068-83

16. Fritsch R, de Krijger I, Fritsch K, George R, Reason B, Kumar MS, et al. RAS and $\mathrm{RHO}$ families of GTPases directly regulate distinct phosphoinositide 3kinase isoforms. Cell. 2013;153(5):1050-63.

17. McCubrey JA, Fitzgerald TL, Yang LV, Lertpiriyapong K, Steelman LS, Abrams SL, et al. Roles of GSK-3 and microRNAs on epithelial mesenchymal transition and cancer stem cells. Oncotarget. 2017;8(8):14221-50.

18. Schwartz S, Wongvipat J, Trigwell CB, Hancox U, Carver BS, RodrikOutmezguine V, et al. Feedback suppression of PI3Kalpha signaling in PTENmutated tumors is relieved by selective inhibition of PI3Kbeta. Cancer Cell. 2015;27(1):109-22.

19. Wang Z, Kim TB, Peng B, Karam J, Creighton C, Joon A, et al. Sarcomatoid renal cell carcinoma has a distinct molecular pathogenesis, driver mutation profile, and transcriptional landscape. Clinical Cancer Res. 2017;23(21):6686-96.

20. Millis SZ, Ikeda S, Reddy S, Gatalica Z, Kurzrock R. Landscape of Phosphatidylinositol-3-kinase pathway alterations across 19784 diverse solid tumors. JAMA Oncol. 2016;2(12):1565-73.

21. Li J, Yan S, Liu Z, Zhou Y, Pan Y, Yuan W, et al. Multiregional sequencing reveals genomic alterations and clonal dynamics in primary malignant melanoma of the esophagus. Cancer Res. 2017;78:338-47. 
22. Saunderson EA, Stepper P, Gomm JJ, Hoa L, Morgan A, Allen MD, et al. Hitand-run epigenetic editing prevents senescence entry in primary breast cells from healthy donors. Nat Commun. 2017:8(1):1450.

23. Wan S, Meyer AS, Weiler SME, Rupp C, Toth M, Sticht C, et al. Cytoplasmic localization of the cell polarity factor Scribble supports liver tumor formation and tumor cell invasiveness. Hepatology (Baltimore, Md). 2017;67:1842-56.

24. Alimonti A, Carracedo A, Clohessy JG, Trotman LC, Nardella C, Egia A, et al. Subtle variations in Pten dose determine cancer susceptibility. Nat Genet. 2010;42(5):454-8.

25. Shen-Li H, Koujak S, Szablocs M, Parsons R. Reduction of Pten dose leads to neoplastic development in multiple organs of Pten (shRNA) mice. Cancer Biol Ther. 2010;10(11):1194-200.

26. Butler MG, Dasouki MJ, Zhou XP, Talebizadeh Z, Brown M, Takahashi TN, et al. Subset of individuals with autism spectrum disorders and extreme macrocephaly associated with germline PTEN tumour suppressor gene mutations. J Med Genet. 2005;42(4):318-21.

27. Pal A, Barber TM, Van de Bunt M, Rudge SA, Zhang Q, Lachlan KL, et al. PTEN mutations as a cause of constitutive insulin sensitivity and obesity. N Engl J Med. 2012;367(11):1002-11.

28. Garcia-Junco-Clemente P, Golshani P. PTEN: a master regulator of neuronal structure, function, and plasticity. Commun Integrative Biol. 2014;7(1):e28358

29. Kwak YG, Song CH, Yi HK, Hwang PH, Kim JS, Lee KS, et al. Involvement of PTEN in airway hyperresponsiveness and inflammation in bronchial asthma. J Clin Invest. 2003;111(7):1083-92.

30. Kuo HM, Lin CY, Lam HC, Lin PR, Chan HH, Tseng JC, et al. PTEN overexpression attenuates angiogenic processes of endothelial cells by blockade of endothelin-1/endothelin B receptor signaling. Atherosclerosis 2012;221(2):341-9.

31. Domanskyi A, Geissler C, Vinnikov IA, Alter H, Schober A, Vogt MA, et al. Pten ablation in adult dopaminergic neurons is neuroprotective in Parkinson's disease models. FASEB J. 2011;25(9):2898-910.

32. Liu B, Li L, Zhang Q, Chang N, Wang D, Shan Y, et al. Preservation of GABAA receptor function by PTEN inhibition protects against neuronal death in ischemic stroke. Stroke. 2010;41(5):1018-26.

33. Knafo S, Sanchez-Puelles C, Palomer E, Delgado I, Draffin JE, Mingo J, et al. PTEN recruitment controls synaptic and cognitive function in Alzheimer's models. Nat Neurosci. 2016;19(3):443-53.

34. Stambolic $V$, MacPherson $D$, Sas D, Lin $Y$, Snow B, Jang $Y$, et al. Regulation of PTEN transcription by p53. Mol Cell. 2001;8(2):317-25.

35. Torres J, Pulido R. The tumor suppressor PTEN is phosphorylated by the protein kinase CK2 at its C terminus. Implications for PTEN stability to proteasome-mediated degradation. J Biol Chem. 2001;276(2):993-8.

36. Folino A, Accomasso L, Giachino C, Montarolo PG, Losano G, Pagliaro P, et al. Apelin-induced cardioprotection against ischaemia/reperfusion injury: roles of epidermal growth factor and Src. Acta Physiol. 2018;222:e13005.

37. Taft RJ, Pheasant M, Mattick JS. The relationship between non-proteincoding DNA and eukaryotic complexity. BioEssays. 2007;29(3):288-99.

38. Esteller M, Pandolfi PP. The Epitranscriptome of noncoding RNAs in Cancer. Cancer Discovery. 2017;7(4):359-68.

39. Telonis AG, Magee R, Loher P, Chervoneva I, Londin E, Rigoutsos I. Knowledge about the presence or absence of miRNA isoforms (isomiRs) can successfully discriminate amongst 32 TCGA cancer types. Nucleic Acids Res. 2017:45(6):2973-85.

40. Ahadi A, Sablok G, Hutvagner G. miRTar2GO: a novel rule-based model learning method for cell line specific microRNA target prediction that integrates Ago2 CLIP-Seq and validated microRNA-target interaction data. Nucleic Acids Res. 2017;45(6):e42

41. Dooley J, Lagou V, Garcia-Perez JE, Himmelreich U, Liston A. miR-29adeficiency does not modify the course of murine pancreatic acinar carcinoma. Oncotarget. 2017;8(16):26911-7.

42. Engreitz JM, Sirokman K, McDonel P, Shishkin AA, Surka C, Russell P, et al. RNA-RNA interactions enable specific targeting of noncoding RNAs to nascent pre-mRNAs and chromatin sites. Cell. 2014;159(1):188-99.

43. Runtsch MC, O'Neill LA. GOTcha: IncRNA-ACOD1 targets metabolism during viral infection. Cell Res. 2018;28:137-8

44. Michelini F, Pitchiaya S, Vitelli V, Sharma S, Gioia U, Pessina F, et al. Damageinduced IncRNAs control the DNA damage response through interaction with DDRNAs at individual double-strand breaks. Nat Cell Biol. 2017;19(12):1400-11.

45. Hill R, Calvopina JH, Kim C, Wang Y, Dawson DW, Donahue TR, et al. PTEN loss accelerates KrasG12D-induced pancreatic cancer development. Cancer Res. 2010;70(18):7114-24
46. Ge Y, Zhang L, Nikolova M, Reva B, Fuchs E. Strand-specific in vivo screen of cancer-associated miRNAs unveils a role for miR-21( *) in SCC progression. Nat Cell Biol. 2016;18(1):111-21.

47. Ma X, Conklin DJ, Li F, Dai Z, Hua X, Li Y, et al. The oncogenic microRNA miR-21 promotes regulated necrosis in mice. Nat Commun. 2015;6:7151.

48. Bhagat TD, Zhou L, Sokol L, Kessel R, Caceres G, Gundabolu K, et al. miR-21 mediates hematopoietic suppression in MDS by activating TGF-beta signaling. Blood. 2013;121(15):2875-81.

49. Kim RY, Horvat JC, Pinkerton JW, Starkey MR, Essilfie AT, Mayall JR, et al. MicroRNA-21 drives severe, steroid-insensitive experimental asthma by amplifying phosphoinositide 3-kinase-mediated suppression of histone deacetylase 2. J Allergy Clin Immunol. 2017;139(2):519-32.

50. Caviglia JM, Yan J, Jang MK, Gwak GY, Affo S, Yu L, et al. MicroRNA-21 and Dicer are Dispensable for Hepatic Stellate Cell Activation and the Development of Liver Fibrosis. Hepatology (Baltimore, Md). 2018;67:2414-29.

51. Shi J, Bei Y, Kong X, Liu X, Lei Z, Xu T, et al. miR-17-3p contributes to exercise-induced cardiac growth and protects against myocardial ischemiareperfusion injury. Theranostics. 2017;7(3):664-76.

52. Zheng $P$, Chen $L$, Yuan $X$, Luo Q, Liu Y, Xie G, et al. Exosomal transfer of tumor-associated macrophage-derived miR-21 confers cisplatin resistance in gastric cancer cells. J Exp Clin Cancer Res. 2017;36(1):53.

53. Liu W, Zhang B, Chen G, Wu W, Zhou L, Shi Y, et al. Targeting miR-21 with Sophocarpine inhibits tumor progression and reverses epithelial-mesenchymal transition in head and neck Cancer. Mol Ther. 2017;25(9):2129-39.

54. Yu G, Yao W, Gumireddy K, Li A, Wang J, Xiao W, et al. Pseudogene PTENP1 functions as a competing endogenous RNA to suppress clear-cell renal cell carcinoma progression. Mol Cancer Ther. 2014;13(12):3086-97.

55. Egawa H, Jingushi K, Hirono T, Ueda Y, Kitae K, Nakata W, et al. The miR-130 family promotes cell migration and invasion in bladder cancer through FAK and Akt phosphorylation by regulating PTEN. Sci Rep. 2016;6:20574.

56. Wei H, Cui R, Bahr J, Zanesi N, Luo Z, Meng W, et al. miR-130a deregulates PTEN and stimulates tumor growth. Cancer Res. 2017;77(22):6168-78.

57. Song CL, Liu B, Shi YF, Liu N, Yan YY, Zhang JC, et al. MicroRNA-130a alleviates human coronary artery endothelial cell injury and inflammatory responses by targeting PTEN via activating PI3K/Akt/eNOS signaling pathway. Oncotarget. 2016;7(44):71922-36.

58. Zhang D, Yang S, Toledo EM, Gyllborg D, Salto C, Carlos Villaescusa J, et al. Niche-derived laminin-511 promotes midbrain dopaminergic neuron survival and differentiation through YAP. Sci Signal. 2017;10(493):eaal4165.

59. Ye L, Wang Y, Nie L, Qian S, Xu M. MiR-130 exerts tumor suppressive function on the tumorigenesis of human non-small cell lung cancer by targeting PTEN. Am J Transl Res. 2017;9(4):1856-65.

60. Tian F, Han Y, Yan X, Zhong D, Yang G, Lei J, et al. Upregulation of microrna-451 increases the sensitivity of A549 cells to radiotherapy through enhancement of apoptosis. Thoracic Cancer. 2016;7(2):226-31.

61. Wu RL, Ali S, Bandyopadhyay S, Alosh B, Hayek K, Daaboul MF, et al. Comparative analysis of differentially expressed miRNAs and their downstream mRNAs in ovarian Cancer and its associated endometriosis. J Cancer Sci Ther. 2015;7(7):258-65.

62. Garofalo M, Di Leva G, Romano G, Nuovo G, Suh SS, Ngankeu A, et al. miR$221 \& 222$ regulate TRAlL resistance and enhance tumorigenicity through PTEN and TIMP3 downregulation. Cancer Cell. 2009;16(6):498-509.

63. Chen J, Zhuang Y, Zhang ZF, Wang $S$, Jin $P, H e ~ C$, et al. Glycine confers neuroprotection through microRNA-301a/PTEN signaling. Mol Brain. 2016;9(1):59.

64. Dou L, Wang S, Sui $X$, Meng $X$, Shen T, Huang $X$, et al. MiR-301a mediates the effect of IL-6 on the AKT/GSK pathway and hepatic glycogenesis by regulating PTEN expression. Cellular Physiol Biochem. 2015;35(4):1413-24.

65. Ma F, Zhang J, Zhong L, Wang L, Liu Y, Wang Y, et al. Upregulated microRNA-301a in breast cancer promotes tumor metastasis by targeting PTEN and activating Wnt/beta-catenin signaling. Gene. 2014;535(2):191-7.

66. Kawano M, Tanaka K, Itonaga I, Iwasaki T, Tsumura H. MicroRNA-301a promotes cell proliferation via PTEN targeting in Ewing's sarcoma cells. Int J Oncol. 2016:48(4):1531-40.

67. Cui L, Li Y, LV X, Li J, Wang X, Lei Z, et al. Expression of MicroRNA-301a and its functional roles in malignant melanoma. Cellular Physiol Biochem. 2016;40(1-2):230-44.

68. Yin $Y$, Cai $X$, Chen $X$, Liang $H$, Zhang $Y$, Li J, et al. Tumor-secreted miR-214 induces regulatory $T$ cells: a major link between immune evasion and tumor growth. Cell Res. 2014;24(10):1164-80.

69. Yang H, Kong W, He L, Zhao JJ, O'Donnell JD, Wang J, et al. MicroRNA expression profiling in human ovarian cancer: miR-214 induces cell survival and cisplatin resistance by targeting PTEN. Cancer Res. 2008;68(2):425-33. 
70. Jindra PT, Bagley J, Godwin JG, lacomini J. Costimulation-dependent expression of microRNA-214 increases the ability of T cells to proliferate by targeting Pten. Journal of immunology (Baltimore, Md : 1950). 2010;185(2):990-7.

71. Lv G, Shao S, Dong H, Bian X, Yang X, Dong S. MicroRNA-214 protects cardiac myocytes against H2O2-induced injury. J Cell Biochem. 2014;115(1):93-101.

72. Wang Y, Xu J, Gao G, Li J, Huang H, Jin H, et al. Tumor-suppressor NFkappaB2 p100 interacts with ERK2 and stabilizes PTEN mRNA via inhibition of miR-494. Oncogene. 2016;35(31):4080-90.

73. Wang X, Zhang X, Ren XP, Chen J, Liu H, Yang J, et al. MicroRNA-494 targeting both proapoptotic and antiapoptotic proteins protects against ischemia/ reperfusion-induced cardiac injury. Circulation. 2010;122(13):1308-18.

74. Fu X, Wen H, Jing L, Yang Y, Wang W, Liang X, et al. MicroRNA-155-5p promotes hepatocellular carcinoma progression by suppressing PTEN through the PI3K/Akt pathway. Cancer Sci. 2017;108:620-31.

75. Miao Y, Zheng W, Li N, Su Z, Zhao L, Zhou H, et al. MicroRNA-130b targets PTEN to mediate drug resistance and proliferation of breast cancer cells via the PI3KJAkt signaling pathway. Sci Rep. 2017;7:41942.

76. Zhang D, Zhou P, Wang W, Wang X, Li J, Sun X, et al. MicroRNA-616 promotes the migration, invasion and epithelial-mesenchymal transition of HCC by targeting PTEN. Oncol Rep. 2016;35(1):366-74.

77. Li J, Yang S, Yan W, Yang J, Qin YJ, Lin XL, et al. MicroRNA-19 triggers epithelial-mesenchymal transition of lung cancer cells accompanied by growth inhibition. Lab Invest J Tech Methods Pathol. 2015;95(9):1056-70.

78. Ke TW, Wei PL, Yeh KT, Chen WT, Cheng YW. MiR-92a promotes cell metastasis of colorectal Cancer through PTEN-mediated PI3KVAKT pathway. Ann Surg Oncol. 2015;22(8):2649-55.

79. Yu T, Liu L, Li J, Yan M, Lin H, Liu Y, et al. MiRNA-10a is upregulated in NSCLC and may promote cancer by targeting PTEN. Oncotarget. 2015;6(30):30239-50.

80. Guo G, Kang Q, Zhu X, Chen Q, Wang X, Chen Y, et al. A long noncoding RNA critically regulates Bcr-Abl-mediated cellular transformation by acting as a competitive endogenous RNA. Oncogene. 2015;34(14):1768-79.

81. Tang J, Li L, Huang W, Sui C, Yang Y, Lin X, et al. MiR-429 increases the metastatic capability of HCC via regulating classic Wnt pathway rather than epithelial-mesenchymal transition. Cancer Lett. 2015;364(1):33-43.

82. Zeitels LR, Acharya A, Shi G, Chivukula D, Chivukula RR, Anandam JL, et al. Tumor suppression by miR-26 overrides potential oncogenic activity in intestinal tumorigenesis. Genes Dev. 2014;28(23):2585-90.

83. Mavrakis KJ, Van Der Meulen J, Wolfe AL, Liu X, Mets E, Taghon T, et al. A cooperative microRNA-tumor suppressor gene network in acute T-cell lymphoblastic leukemia (T-ALL). Nat Genet. 2011;43(7):673-8.

84. Wang LS, Li L, Li L, Chu S, Shiang KD, Li M, et al. MicroRNA-486 regulates normal erythropoiesis and enhances growth and modulates drug response in CML progenitors. Blood. 2015;125(8):1302-13.

85. Longacre M, Snyder NA, Housman G, Leary M, Lapinska K, Heerboth S, et al. A comparative analysis of genetic and epigenetic events of breast and ovarian Cancer related to tumorigenesis. Int J Mol Sci. 2016;17(5):E759.

86. Tagde A, Rajabi H, Stroopinsky D, Gali R, Alam M, Bouillez A, et al. MUC1-C induces DNA methyltransferase 1 and represses tumor suppressor genes in acute myeloid leukemia. Oncotarget. 2016;7(26):38974-87.

87. Yang YL, Wang FS, Li SC, Tiao MM, Huang YH. MicroRNA-29a alleviates bile duct ligation exacerbation of hepatic fibrosis in mice through epigenetic control of methyltransferases. Int J Mol Sci. 2017;18(1):E192.

88. Zheng J, Wu C, Lin Z, Guo Y, Shi L, Dong P, et al. Curcumin up-regulates phosphatase and tensin homologue deleted on chromosome 10 through microRNA-mediated control of DNA methylation--a novel mechanism suppressing liver fibrosis. FEBS J. 2014;281(1):88-103.

89. Wang L, Yao J, Sun H, He K, Tong D, Song T, et al. MicroRNA-101 suppresses progression of lung cancer through the PTEN/AKT signaling pathway by targeting DNA methyltransferase 3A. Oncol Lett. 2017;13(1):329-38.

90. Yan F, Shen N, Pang J, Xie D, Deng B, Molina JR, et al. Restoration of miR101 suppresses lung tumorigenesis through inhibition of DNMT3adependent DNA methylation. Cell Death Dis. 2014;5:e1413.

91. Qadir XV, Han C, Lu D, Zhang J, Wu T. miR-185 inhibits hepatocellular carcinoma growth by targeting the DNMT1/PTEN/Akt pathway. Am J Pathol. 2014;184(8):2355-64.

92. Cesana M, Cacchiarelli D, Legnini I, Santini T, Sthandier O, Chinappi M, et al. A long noncoding RNA controls muscle differentiation by functioning as a competing endogenous RNA. Cell. 2011;147(2):358-69.

93. Karreth FA, Tay Y, Perna D, Ala U, Tan SM, Rust AG, et al. In vivo identification of tumor- suppressive PTEN ceRNAs in an oncogenic BRAFinduced mouse model of melanoma. Cell. 2011;147(2):382-95.
94. Shen L, Wang Q, Liu R, Chen Z, Zhang X, Zhou P, et al. LncRNA Inc-RI regulates homologous recombination repair of DNA double-strand breaks by stabilizing RAD51 mRNA as a competitive endogenous RNA. Nucleic Acids Res. 2018;46:717-29.

95. Tay Y, Kats L, Salmena L, Weiss D, Tan SM, Ala U, et al. Coding-independent regulation of the tumor suppressor PTEN by competing endogenous mRNAs. Cell. 2011;147(2):344-57.

96. Gao L, Ren W, Zhang L, Li S, Kong X, Zhang H, et al. PTENp1, a natural sponge of miR-21, mediates PTEN expression to inhibit the proliferation of oral squamous cell carcinoma. Mol Carcinog. 2017;56(4):1322-34.

97. Chen CL, Tseng YW, Wu JC, Chen GY, Lin KC, Hwang SM, et al. Suppression of hepatocellular carcinoma by baculovirus-mediated expression of long noncoding RNA PTENP1 and MicroRNA regulation. Biomaterials. 2015;44:71-81.

98. Poliseno L, Salmena L, Zhang J, Carver B, Haveman WJ, Pandolfi PP. A coding-independent function of gene and pseudogene mRNAs regulates tumour biology. Nature. 2010;465(7301):1033-8.

99. Zhang R, Guo Y, Ma Z, Ma G, Xue Q, Li F, et al. Long non-coding RNA PTENP1 functions as a ceRNA to modulate PTEN level by decoying miR106b and miR-93 in gastric cancer. Oncotarget. 2017;8(16):26079-89.

100. Phelps M, Coss C, Wang H, Cook M. Registered report: coding-independent regulation of the tumor suppressor PTEN by competing endogenous mRNAs. elife. 2016;5:e12470.

101. Khan I, Kerwin J, Owen K, Griner E. Registered report: a coding-independent function of gene and pseudogene mRNAs regulates tumour biology. elife. 2015;4:e13015.

102. Gupta RA, Shah N, Wang KC, Kim J, Horlings HM, Wong DJ, et al. Long noncoding RNA HOTAIR reprograms chromatin state to promote cancer metastasis. Nature. 2010;464(7291):1071-6.

103. Sparmann A, van Lohuizen M. Polycomb silencers control cell fate, development and cancer. Nat Rev Cancer. 2006;6(11):846-56.

104. Rinn JL, Kertesz M, Wang JK, Squazzo SL, Xu X, Brugmann SA, et al. Functional demarcation of active and silent chromatin domains in human HOX loci by noncoding RNAs. Cell. 2007;129(7):1311-23.

105. Lai $Y, H e S, M a L$, Lin $H$, Ren $B$, Ma J, et al. HOTAIR functions as a competing endogenous RNA to regulate PTEN expression by inhibiting miR-19 in cardiac hypertrophy. Mol Cell Biochem. 2017:432(1-2):179-87.

106. Sui J, Yang X, Qi W, Guo K, Gao Z, Wang L, et al. Long non-coding RNA Linc-USP16 functions as a tumour suppressor in hepatocellular carcinoma by regulating PTEN expression. Cell Physiol Biochem. 2017; 44(3):1188-98.

107. Ba Z, Gu L, Hao S, Wang X, Cheng Z, Nie G. Downregulation of IncRNA CASC2 facilitates osteosarcoma growth and invasion through miR-181a. Cell Prolif. 2018;51(1):e12409.

108. Liao Y, Shen L, Zhao H, Liu Q, Fu J, Guo Y, et al. LncRNA CASC2 interacts with miR-181a to modulate glioma growth and resistance to TMZ through PTEN pathway. J Cell Biochem. 2017;118(7):1889-99.

109. Feng Y, Zou W, Hu C, Li G, Zhou S, He Y, et al. Modulation of CASC2/miR21/PTEN pathway sensitizes cervical cancer to cisplatin. Arch Biochem Biophys. 2017;623-624:20-30.

110. Yang NQ, Luo XJ, Zhang J, Wang GM, Guo JM. Crosstalk between Meg3 and miR-1297 regulates growth of testicular germ cell tumor through PTEN/ PI3K AKT pathway. Am J Transl Res. 2016;8(2):1091-9.

111. Liu C, Liu Z, Li X, Tang X, He J, Lu S. MicroRNA-1297 contributes to tumor growth of human breast cancer by targeting PTEN/PI3K/AKT signaling. Oncol Rep. 2017:38(4):2435-43.

112. Qin N, Tong GF, Sun LW, Xu XL. Long noncoding RNA MEG3 suppresses glioma cell proliferation, migration, and invasion by acting as a competing endogenous RNA of miR-19a. Oncol Res. 2017;25(9):1471-8.

113. Wu Z, He Y, Li D, Fang $X$, Shang T, Zhang $H$, et al. Long noncoding RNA MEG3 suppressed endothelial cell proliferation and migration through regulating miR-21. Am J Transl Res. 2017;9(7):3326-35.

114. Li W, Zhai L, Wang H, Liu C, Zhang J, Chen W, et al. Downregulation of LncRNA GAS5 causes trastuzumab resistance in breast cancer. Oncotarget. 2016;7(19):27778-86.

115. Hu L, Ye H, Huang G, Luo F, Liu Y, Liu Y, et al. Long noncoding RNA GAS5 suppresses the migration and invasion of hepatocellular carcinoma cells via miR-21. Tumour Biol. 2016;37(2):2691-702.

116. Cao L, Chen J, Ou B, Liu C, Zou Y, Chen Q. GAS5 knockdown reduces the chemo-sensitivity of non-small cell lung cancer (NSCLC) cell to cisplatin (DDP) through regulating miR-21/PTEN axis. Biomed Pharmacother. 2017:93: 570-9. 
117. Tao H, Zhang JG, Qin RH, Dai C, Shi P, Yang JJ, et al. LncRNA GAS5 controls cardiac fibroblast activation and fibrosis by targeting miR-21 via PTEN/MMP2 signaling pathway. Toxicology. 2017;386:11-8.

118. Guo C, Song WQ, Sun P, Jin L, Dai HY. LncRNA-GAS5 induces PTEN expression through inhibiting miR-103 in endometrial cancer cells. J Biomed Sci. 2015;22:100

119. Yang W, Hong L, Xu X, Wang Q, Huang J, Jiang L. LncRNA GAS5 suppresses the tumorigenesis of cervical cancer by downregulating miR-196a and miR205. Tumour Biol. 2017;39(7):1010428317711315.

120. Gao ZQ, Wang JF, Chen DH, Ma XS, Wu Y, Tang Z, et al. Long non-coding RNA GAS5 suppresses pancreatic cancer metastasis through modulating miR-32-5p/PTEN axis. Cell Biosci. 2017;7:66.

121. Chang S, Chen B, Wang X, WU K, Sun Y. Long non-coding RNA XIST regulates PTEN expression by sponging miR-181a and promotes hepatocellular carcinoma progression. BMC Cancer. 2017;17(1):248

122. Gu S, Xie R, Liu X, Shou J, Gu W, Che X. Long coding RNA XIST contributes to neuronal apoptosis through the downregulation of AKT phosphorylation and is negatively regulated by miR-494 in rat spinal cord injury. Int J Mol Sci. 2017;18(4):E732.

123. Yang C, Wang G, Yang J, Wang L. Long noncoding RNA NBAT1 negatively modulates growth and metastasis of osteosarcoma cells through suppression of miR-21. Am J Cancer Res. 2017;7(10):2009-19.

124. Erho N, Crisan A, Vergara IA, Mitra AP, Ghadessi M, Buerki C, et al. Discovery and validation of a prostate cancer genomic classifier that predicts early metastasis following radical prostatectomy. PLoS One. 2013;8(6):e66855.

125. Taylor BS, Schultz N, Hieronymus H, Gopalan A, Xiao Y, Carver BS, et al. Integrative genomic profiling of human prostate cancer. Cancer Cell. 2010; 18(1):11-22.

126. Du Z, Sun T, Hacisuleyman E, Fei T, Wang X, Brown M, et al. Integrative analyses reveal a long noncoding RNA-mediated sponge regulatory network in prostate cancer. Nat Commun. 2016;7:10982.

127. Li J, An G, Zhang M, Ma Q. Long non-coding RNA TUG1 acts as a miR-26a sponge in human glioma cells. Biochem Biophys Res Commun. 2016;477(4):743-8.

128. Xia T, Liao Q, Jiang X, Shao Y, Xiao B, Xi Y, et al. Long noncoding RNA associatedcompeting endogenous RNAs in gastric cancer. Sci Rep. 2014:4:6088.

129. Qiao Q, Li H. LncRNA FER1L4 suppresses cancer cell proliferation and cycle by regulating PTEN expression in endometrial carcinoma. Biochem Biophys Res Commun. 2016;478(2):507-12.

130. Yue B, Sun B, Liu C, Zhao S, Zhang D, Yu F, et al. Long non-coding RNA Fer-1-like protein 4 suppresses oncogenesis and exhibits prognostic value by associating with miR-106a-5p in colon cancer. Cancer Sci. 2015;106(10):1323-32.

131. Xia T, Chen S, Jiang Z, Shao Y, Jiang X, Li P, et al. Long noncoding RNA FER1L4 suppresses cancer cell growth by acting as a competing endogenous RNA and regulating PTEN expression. Sci Rep. 2015;5:13445.

132. Yu F, Lu Z, Chen B, Dong P, Zheng J. Identification of a novel lincRNA-p21miR-181b-PTEN signaling Cascade in liver fibrosis. Mediat Inflamm. 2016; 2016:9856538.

133. Johnsson P, Ackley A, Vidarsdottir L, Lui WO, Corcoran M, Grander D, et al. A pseudogene long-noncoding-RNA network regulates PTEN transcription and translation in human cells. Nat Struct Mol Biol. 2013;20(4):440-6.

134. Yu F, Chen B, Dong P, Zheng J. HOTAIR epigenetically modulates PTEN expression via MicroRNA-29b: a novel mechanism in regulation of liver fibrosis. Mol Ther. 2017;25(1):205-17.

135. Li D, Feng J, Wu T, Wang Y, Sun Y, Ren J, et al. Long intergenic noncoding RNA HOTAIR is overexpressed and regulates PTEN methylation in laryngeal squamous cell carcinoma. Am J Pathol. 2013;182(1):64-70.

136. Lister N, Shevchenko G, Walshe JL, Groen J, Johnsson P, Vidarsdottir L, et al. The molecular dynamics of long noncoding RNA control of transcription in PTEN and its pseudogene. Proc Natl Acad Sci U S A. 2017:114(37):9942-7.

137. Wang WJ, Yang W, Ouyang ZH, Xue JB, Li XL, Zhang J, et al. MiR-21 promotes ECM degradation through inhibiting autophagy via the PTEN/akt/ mTOR signaling pathway in human degenerated NP cells. Biomed Pharmacother. 2018:99:725-34

138. Li L, Wang Z, Hu X, Wan T, Wu H, Jiang W, et al. Human aortic smooth muscle cell-derived exosomal miR-221/222 inhibits autophagy via a PTEN/ Akt signaling pathway in human umbilical vein endothelial cells. Biochem Biophys Res Commun. 2016;479(2):343-50

139. Yan $L$, Cao R, Liu Y, Wang L, Pan B, Lv X, et al. MiR-21-5p links epithelialmesenchymal transition phenotype with stem-like cell signatures via AKT signaling in keloid keratinocytes. Sci Rep. 2016;6:28281.
140. Bahena-Ocampo I, Espinosa M, Ceballos-Cancino G, Lizarraga F, CamposArroyo D, Schwarz A, et al. miR-10b expression in breast cancer stem cells supports self-renewal through negative PTEN regulation and sustained AKT activation. EMBO Rep. 2016;17(5):648-58.

141. Yuan L, LV Y, Li H, Gao H, Song S, Zhang Y, et al. Deubiquitylase OTUD3 regulates PTEN stability and suppresses tumorigenesis. Nat Cell Biol. 2015; 17(9):1169-81.

142. Peyrou M, Bourgoin L, Poher AL, Altirriba J, Maeder C, Caillon A, et al. Hepatic PTEN deficiency improves muscle insulin sensitivity and decreases adiposity in mice. J Hepatol. 2015;62(2):421-9.

143. Xu L, Fan Q, Wang X, Li L, Lu X, Yue Y, et al. Ursolic acid improves podocyte injury caused by high glucose. Nephrol Dial Transplant. 2017;32(8):1285-93.

144. Zhou X, Ren Y, Liu A, Jin R, Jiang Q, Huang Y, et al. WP1066 sensitizes oral squamous cell carcinoma cells to cisplatin by targeting STAT3/miR-21 axis. Sci Rep. 2014:4:7461.

145. Nip H, Dar AA, Saini S, Colden M, Varahram S, Chowdhary H, et al. Oncogenic microRNA-4534 regulates PTEN pathway in prostate cancer. Oncotarget. 2016;7(42):68371-84.

146. Liang Z, Li Y, Huang K, Wagar N, Shim H. Regulation of miR-19 to breast cancer chemoresistance through targeting PTEN. Pharm Res. 2011;28(12): 3091-100

Ready to submit your research? Choose BMC and benefit from:

- fast, convenient online submission

- thorough peer review by experienced researchers in your field

- rapid publication on acceptance

- support for research data, including large and complex data types

- gold Open Access which fosters wider collaboration and increased citations

- maximum visibility for your research: over $100 \mathrm{M}$ website views per year

At BMC, research is always in progress.

Learn more biomedcentral.com/submissions 